Proc. Ladian Acad. Sci, Vol. 88 A, Part I, Number 4, August 1979, pp. 239-247, - printod in India.

\title{
Spectroscopic properties of molecules related to hindered isomers of retinal
}

V RAMAMURTHY and R S H LIU*

Department of Organic Chemistry, Indian Institute of Science, Bangalore 560012

- Department of Chemistry, University of Hawaii, Honolulu, USA

MS received 23 January 1979

Abetrrat. Proton and ${ }^{18} \mathrm{C}$ NMR study of molecules related to retinal has been carried out. The characteristic differences in spectral behaviour among 7-trans and 7-cis isomers have been established which would be useful in determining the structure of new isomers and identifying components in a mixture. Through coupling constant measurements and DNMR study it is clearly established that 7-cis isomers of B-ionyl derivatives and in turn 7-cis isomers of retinyl derivatives prefer a nonplanar arrangement and this non-planarity brings about resonance destabilisation.

Keywords. ${ }^{1} \mathrm{H} ;{ }^{18} \mathrm{C}$ NMR study; DNMR of ionyl derivatives.

\section{Introduction}

Retinal 1, one of the biologically important molecules, theoretically can exist in sixteen geometrical isomeric forms. According to Pauling $(1939,1949)$ the possibility of forming cis double bonds at $C_{7}$ and $C_{11}$ pasitions has to be discarded on account of the steric hindrance existing in these forms which would not allow the resonance phenomena. However, two hindered retinals having 11-cis configuration have since been synthesised (Orshnik 1956). Construction of the Dreiding models and spectroscopic data clearly indicate that the distortion of the side chain may partly reduce the possibility of resonance for these compounds (Patel 1969). On the other hand, all attempts to synthesise the 7-cis isomers through conventional means were unsuccessful (Wald et al 1955; Russel and Weeden 1969; Fagle and Karrer 1961). The rationale for the failure has been the lack of stability due to lass of resonance stabilisation brought about by the forced skewed geometry.

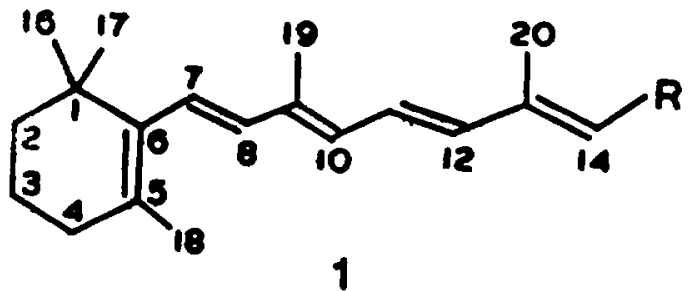


Recently, we have synthesised 7-cis isomers of retinal and related malecules through a navel "one way sensitised geometric photoisomerisation" (Ramamurthy and Liu 1976; Ramamurthy et al 1975). The ready availability of these molecules have allowed us to test the prediction of steric hindrance in these isomers. We have studied the 7 -cis isomers of $\beta$-ionyl derivatives $(2-10)$ possessing the basic framework of 7-cis retinals and the results are expected to show the fundamental structural features in the $\mathrm{C}_{5}-\mathrm{C}_{3}$ region of 7 -cis-retinal isomers.

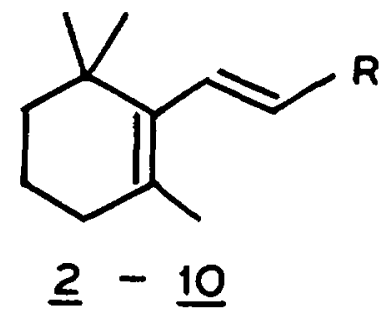

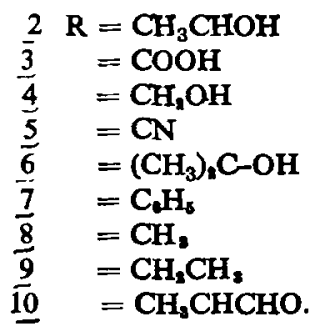

In this paper we present our spectral data on these molecules which point out the existence of steric crowding resulting in non-planar molecules as was originally suggested.

\section{Results and discussion}

\subsection{Proton NMR study}

Molecules 2-10 were synthesised and purified by the published procedures (Ramamurthy and Liu 1976; Ramamurthy et al 1975). Proton and ${ }^{13} \mathrm{C} \mathrm{nmr}$ data are presented in tables 1 and 2 respectively. The following general observations can be made on perusal of table 1 . We believe that these gneralisations will be useful in determining the structure of new isomers and identifying components in a mixture.

(i) The $\mathrm{CH}_{3}-18$ and $\mathrm{CH}_{3}-19$ of 7 -cis isomers resonate at a higher field $(\triangle \delta$ $0.2 \mathrm{ppm}$ ) than trans isomers.

(ii) Proton attached to $\mathrm{C}_{7}\left(\mathrm{H}_{7}\right)$ is consistently shifted upfield in 7-cis isomers compared to 7-trans isomers.

(iii) Proton attached to $\mathrm{C}_{8}\left(\mathrm{H}_{8}\right)$ is also shifted upfield in 7-cis isomers but only to a small degree.

It is not surprising to notice only a small difference in chemical shifts between 7-trans and 7-cis isomers for all ather protons, except $\mathrm{H}_{7}, \mathrm{H}_{8}, \mathrm{CH}_{3}-18$ and $\mathrm{CH}_{3}-19$ as the geometry around chain and the ring would not be expected to affect their magnetic environments considerably. Had the 7-cis isomers been planar, the $\mathrm{CH}_{3}-18$ and $\mathrm{CH}_{3}-19$ would be expected to resonate downfield compared to 7-trans isomers, such shifts being due to very close steric proximity of these groups. On the other hand, the abserved upfield shifts clearly rules out the steric crowding between $\mathrm{CH}_{3}-18$ and $\mathrm{CH}_{3}-19$ which must have been relieved by twisting about 6-7 band. The upfield shift must be due to the shielding of $\mathrm{CH}_{3}-18$ by the side chain which is out of plane with respect to the ting. The upfield shift of $\mathrm{H}_{7}$ in 7-cis isomers compared to 7-trans isomers is also consistent with the twist 
Table 1. NMR spectral characteristics of $\beta$-ionyl derivatives.

\begin{tabular}{|c|c|c|c|c|c|c|c|c|c|}
\hline \multirow[b]{2}{*}{ Compound } & \multirow[b]{2}{*}{$\mathrm{H}_{7}$} & \multicolumn{4}{|c|}{ Chemical shifts } & \multirow[b]{2}{*}{$\mathbf{H}_{7}$} & \multirow[b]{2}{*}{$\mathbf{H}_{\mathbf{B}}$} & \multicolumn{2}{|c|}{ (Trans-cis) } \\
\hline & & $\mathbf{H}_{\mathbf{z}}$ & $\mathrm{CH}_{3}-18$ & $\mathrm{CH}_{\mathbf{3}}-19$ & $J_{78 \mathbf{8 x}}$ & & & $\mathrm{CH}_{8}-18$ & $\mathrm{CH}_{3}-19$ \\
\hline 2 trans & 6.01 & $5 \cdot 41$ & $1 \cdot 64$ & $1 \cdot 24$ & 16 & & & & \\
\hline cis & $5 \cdot 75$ & $5 \cdot 45$ & $1 \cdot 54$ & $1 \cdot 16$ & $11 \cdot 5$ & $0 \cdot 26$ & -0.04 & $0 \cdot 10$ & 0.08 \\
\hline 3 trans & $7 \cdot 02$ & $5 \cdot 81$ & $1 \cdot 50$ & .. & $15 \cdot 5$ & & & & \\
\hline cis & $6 \cdot 52$ & $5 \cdot 76$ & $1 \cdot 48$ & & 12 & 0.49 & 0.05 & 0.02 & $\cdots$ \\
\hline 4 trans & 6.04 & $5 \cdot 51$ & $1 \cdot 80$ & $4 \cdot 12$ & 16 & & & & \\
\hline cis & $5 \cdot 79$ & $5 \cdot 57$ & 1.42 & $3 \cdot 90$ & 11 & 0.25 & -0.06 & 0.38 & $0 \cdot 22$ \\
\hline 5 trans & $7 \cdot 10$ & $5 \cdot 30$ & 1.82 & . & 17 & & & & \\
\hline cis & $6 \cdot 84$ & $5 \cdot 46$ & $1 \cdot 76$ & & 11 & 0.26 & -0.16 & 0.06 & . \\
\hline 6 trans & 6.03 & $5 \cdot 53$ & 1.66 & $1 \cdot 34$ & $16 \cdot 2$ & & & & \\
\hline cis & $5 \cdot 71$ & $5 \cdot 46$ & $1 \cdot 70$ & $1 \cdot 23$ & $12 \cdot 5$ & 0.32 & 0.07 & -0.04 & $0 \cdot 11$ \\
\hline 7 trans & $6 \cdot 60$ & 6.35 & $1 \cdot 80$ & .. & 17 & & & & \\
\hline & 6.00 & 0.34 & & & 12 & 0.00 & +0.01 & 0.20 & $\cdots$ \\
\hline 8 trans & $5 \cdot 73$ & $5 \cdot 25$ & $1 \cdot 60$ & $1 \cdot 72$ & 16 & & & & \\
\hline cis & $5 \cdot 83$ & $5 \cdot 55$ & $1 \cdot 48$ & $1 \cdot 62$ & 12 & $-0 \cdot 10$ & $-0 \cdot 30$ & $0 \cdot 12$ & .. \\
\hline 9 trans & $5 \cdot 73$ & $5 \cdot 32$ & $1 \cdot 58$ & $\cdots$ & 17 & & & & \\
\hline$c i s$ & 5.65 & $5 \cdot 29$ & $1 \cdot 40$ & & 12 & 0.08 & 0.03 & 0.18 & .. \\
\hline 10 trans & 5.91 & $5 \cdot 19$ & 1.60 & $1 \cdot 12$ & 16 & & & & \\
\hline$c i s$ & 6.02 & $5 \cdot 28$ & $1 \cdot 52$ & $1 \cdot 06$ & 11 & -0.11 & -0.09 & 0.08 & 0.06 \\
\hline
\end{tabular}

around 6-7 bond. Because of this twist, a good overlap of $\pi$ orbitals extends only from $\mathrm{C}_{7}$ to the rest of the chain and under these conditions $\mathrm{H}_{7}$ would be a terminal polyene proton and should appear at a higher field than if it were in the middle of a polyene chain. Thus proton nmr signals are consistent with nonplanar 7-cis isomers.

\section{2. ${ }^{13} \mathrm{C} N M R$ study}

It is now well established that steric crowding and resonance effect play an important role in the ${ }^{18} \mathrm{C}$ resonance (Stothers 1972). Therefore, a correlation of ${ }^{18} \mathrm{C}$ chemical shifts of 7-trans and 7-cis isomers of $\beta$-ionyl derivatives is expected to reveal the presence of steric hindrance in 7-cis isomers, if any, and the nature of steric release. The following general procedure has been employed for the assignment of each of the ${ }^{13} \mathrm{C}$ spectra reported here. First an initial and possibly tentative assignment of the resanances in the noise decoupled spectrum was made based on comparison with model compounds and known substituent shifts 
Table 2. ${ }^{18} \mathrm{C}$ chemical shifts of $\beta$-ionyl derivatives.

\begin{tabular}{|c|c|c|c|c|c|c|}
\hline \multirow[b]{2}{*}{ Carbon } & \multicolumn{3}{|c|}{$R=C N(5)$} & \multicolumn{3}{|c|}{$R=C O O H(3)$} \\
\hline & Trans & Cis & $(\mathrm{T}-\mathrm{C})$ & Trans & Cis & $(\mathrm{T}-\mathrm{C})$ \\
\hline$C_{1}$ & 33.817 & $34 \cdot 169$ & 0.35 & $34 \cdot 08$ & $34 \cdot 345$ & -0.265 \\
\hline $\mathrm{C}_{2}$ & $39 \cdot 629$ & $38 \cdot 748$ & -0.881 & 39.893 & 38.925 & 0.968 \\
\hline $\mathrm{C}_{8}$ & $18 \cdot 846$ & $19 \cdot 022$ & -0.176 & 18.977 & $19 \cdot 022$ & 0.045 \\
\hline $\mathrm{C}_{4}$ & $33 \cdot 288$ & $32 \cdot 232$ & 1.05 & $33 \cdot 640$ & $31 \cdot 879$ & $1 \cdot 76$ \\
\hline $\mathrm{C}_{6}$ & $136 \cdot 324$ & $132 \cdot 802$ & $3 \cdot 52$ & $136 \cdot 456$ & $129 \cdot 632$ & 6.82 \\
\hline C. & 135.619 & $134 \cdot 739$ & -0.88 & $135 \cdot 751$ & $133 \cdot 683$ & 2.06 \\
\hline $\mathrm{C}_{7}$ & $149 \cdot 534$ & $150 \cdot 591$ & $-1 \cdot 057$ & $146 \cdot 364$ & 0.043 & 0.043 \\
\hline $\mathrm{C}_{\mathrm{s}}$ & $100 \cdot 570$ & $101 \cdot 803$ & $-1 \cdot 233$ & 120.956 & $121 \cdot 529$ & -0.573 \\
\hline $\mathrm{C}_{\mathrm{g}}$ & $117 \cdot 655$ & $116 \cdot 422$ & $-1 \cdot 233$ & $172 \cdot 563$ & $171 \cdot 198$ & $1 \cdot 365$ \\
\hline$C_{10}$ & $28 \cdot 533$ & $28 \cdot 351$ & $0 \cdot 176$ & $28 \cdot 708$ & $28 \cdot 357$ & $0 \cdot 351$ \\
\hline$C_{17}$ & 28.533 & $28 \cdot 357$ & $0 \cdot 176$ & $28 \cdot 708$ & $28 \cdot 357$ & $0 \cdot 351$ \\
\hline \multirow[t]{2}{*}{$\mathrm{C}_{18}$} & $21 \cdot 311$ & $21 \cdot 311$ & .. & $21 \cdot 619$ & $21 \cdot 135$ & 0.484 \\
\hline & \multicolumn{3}{|c|}{$\mathrm{R}=\mathrm{CH}_{2} \mathrm{CHOH}(2)$} & \multicolumn{3}{|c|}{$\mathrm{R}=\left(\mathrm{CH}_{8}\right)_{2} \mathrm{C}-\mathrm{OH}(\underline{6})$} \\
\hline$C_{1}$ & $34 \cdot 0$ & $34 \cdot 036$ & .. & 33.993 & $34 \cdot 433$ & -0.44 \\
\hline$C_{2}$ & $39 \cdot 717$ & $39 \cdot 517$ & 0.20 & $39 \cdot 453$ & $39 \cdot 101$ & 0.352 \\
\hline $\mathrm{C}_{3}$ & $19 \cdot 46$ & $19 \cdot 46$ & & $19 \cdot 374$ & $19 \cdot 109$ & 0.265 \\
\hline $\mathrm{C}_{4}$ & $32 \cdot 848$ & $32 \cdot 44$ & 0.448 & $32 \cdot 672$ & $31 \cdot 967$ & 0.705 \\
\hline$C_{s}$ & $126 \cdot 902$ & $126 \cdot 902$ & 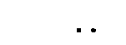 & $127 \cdot 429$ & $129 \cdot 631$ & $-2 \cdot 202$ \\
\hline $\mathrm{C}_{\text {. }}$ & $136 \cdot 765$ & $135 \cdot 00$ & $1 \cdot 765$ & $123 \cdot 643$ & $122 \cdot 410$ & $1 \cdot 23$ \\
\hline$C_{7}$ & $126 \cdot 401$ & 126.902 & -0.501 & $123 \cdot 643$ & $122 \cdot 410$ & $1 \cdot 233$ \\
\hline $\mathrm{C}_{\mathrm{B}}$ & $137 \cdot 409$ & $135 \cdot 55$ & $1 \cdot 859$ & $141 \cdot 784$ & $138 \cdot 458$ & $3 \cdot 326$ \\
\hline$C_{0}$ & 68.954 & 66.90 & 2.05 & $70 \cdot 804$ & $73 \cdot 006$ & $-2 \cdot 202$ \\
\hline $\mathrm{C}_{16}$ & 28.796 & $28 \cdot 5$ & 0.296 & $28 \cdot 709$ & $30 \cdot 646$ & .. \\
\hline$C_{17}$ & $28 \cdot 796$ & $28 \cdot 5$ & 0.296 & $28 \cdot 709$ & $29 \cdot 413$ & .. \\
\hline $\mathrm{C}_{28}$ & $21 \cdot 75$ & $21 \cdot 7$ & 0.05 & $21 \cdot 311$ & $22 \cdot 368$ & 1.057 \\
\hline$C_{19}$ & 23.877 & .. & .. & $29 \cdot 942$ & $28 \cdot 973$ & .. \\
\hline$C_{20}$ & .. & . & . & $29 \cdot 942$ & $28 \cdot 709$ & $\cdots$ \\
\hline
\end{tabular}

(Jantelat et al 1970). An off resonance proton decoupled spectrum provides a check on the preliminary choice and separates the carbons according to their degree of substitution.

Inspection of table 2 reveals the following with respect to ${ }^{12} \mathrm{C}$-spectral data of $\beta$-ionyl derivatives.

(i) The $C_{1}$ and $C_{3}$ chemical shifts are not considerably affected by the geometry around 7-8 double bond.

(ii) The $\mathrm{C}_{4}, \mathrm{C}_{4}$ and $\mathrm{C}_{\mathbf{a}}$ show a consistently small upfield shift for 7-cis isomers when compared to the trans isomers in all the compounds.

(iii) $\mathrm{C}_{5}$ shows a large upfield shift for 7-cis isomers of $\underline{3}$ and 5 ( $R=\mathrm{COOH}$ and $\mathrm{CN}$ ) and downfield shift for 7-cis isomers of $\underline{2}, 4$ and $\underline{6}\left[\mathrm{R}=\mathrm{CH}_{2} \mathrm{CHOH}\right.$, $\left.\mathrm{CH}_{2} \mathrm{OH},\left(\mathrm{CH}_{8}\right)_{2} \mathrm{C}-\mathrm{OH}\right]$.

(iv) $\mathrm{C}_{7}$ does not show any consistency in its chemical shift differences between cis and trans isomers. On the other hand, $\mathrm{C}_{8}$ is shifted upfield for 7-cis isomers of $\underline{2}, \underline{4}$ and $\underline{6}$ and downfield for 7 -cis isomers of $\underline{3}$ and $\underline{5}$. 
(v) $C_{8}$ shows a large upfield shift for all 7-cis isomers compared to 7-trans isomers.

(vi) $\mathrm{C}_{18}, \mathrm{C}_{17}$ and $\mathrm{C}_{1}$, are not affected by the geometry around 7-8 double bond.

The nonplanarity of 7-cis isomers is clearly revealed by the independence of the chemical shifts of $C_{10}, C_{17}$ and $C_{19}$ of the geometry of 7-8 band. Had it been planar, due to the large steric hindrance between these methyl groups and substituents on $\mathrm{C}_{\mathrm{g}}$ in 7-cis isomers, they would be expected to resonate at higher field. The large steric hindrance present in 7-cis isomers is relieved by twisting about 6-7 single bond as is clearly illustrated by the chemical shift data of $\mathrm{C}_{5}$. The large upfield shift of $\mathrm{C}_{5}$ in 7-cis isomers of 3 and $5(\mathrm{R}=\mathrm{COOH}, \mathrm{CN})$ must be due to the absence of resonance effect resulting from twisting of 6-7 bond as shown in equations (1) and (2).

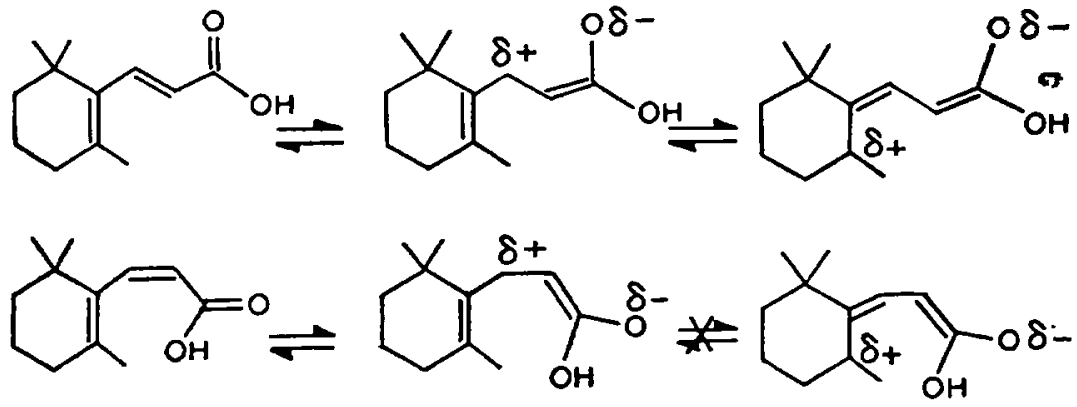

The upfield shift of $\mathrm{C}_{6}$ in all 7-cis compounds compared to 7-trans isomers must be due to the steric crowding between $C_{b}$ and substituents at $C_{8}$ in the nonplanar 7-cis isomers and in agreement with this $C_{9}$ also shows an upfield shift.

Thus bath proton and ${ }^{18} \mathrm{C}$ nmr data are consistent with non-planar 7-cis $\beta$-ionyl derivatives with twisting around 6-7 single bond. Confirmation of this trend is provided by the DNMR (proton and ${ }^{13} \mathrm{C}$ ) and coupling constant data as described below.

\subsection{Coupling constant measurements}

It is known from theoretical and experimental studies that long range proton couplings of the hamoallylic type in which there are five intervening bonds are usually dominated by a $\pi$ contribution such that

$$
\begin{aligned}
& J_{\mathrm{ma}^{2}}(c i s)=J_{\mathrm{na}^{2}}=A \sin ^{2} \Phi \sin ^{2} \Phi^{\prime}, \\
& J_{\mathrm{Hax}^{2}}(\text { trans })=J_{\mathrm{Fa}^{2}}+B=A \sin ^{2} \Phi \sin ^{2} \Phi^{\prime}+B,
\end{aligned}
$$

where $\Phi$ and $\Phi^{\prime}$ are dihedral angles and $A$ is in the range of 5-8 Hz. We have attempted to use the above correlation to obtain the ring-chain dikedral angles in 7-cis isomers and the results are presented in table 3. The coupling between $\mathrm{H}_{7}$ and $\mathrm{CH}_{2}-4,4^{\prime}$ and $\mathrm{CH}_{3}-18$ was extracted by decoupling experiments as illustrated in figure 1 for 6 . The coupling of the methylene group $\mathrm{CH}_{2}-4,4^{\prime}$ and the methyl group $\mathrm{CH}_{3}-18$ with $\mathrm{H}_{7}$ should be governed by the above equations (3) and (4) with $\Phi$ identified as the ring torsional angle and $\Phi^{\prime}$ as that of the hydrogens in $\mathrm{CH}_{2}-4,4^{\prime}$ ar $\mathrm{CH}_{8}-18$ relative to the $\mathrm{C}_{4}-\mathrm{C}_{5}-\mathrm{C}_{8}$ plane or the $\mathrm{CH}_{8}-\mathrm{C}_{5}-\mathrm{C}_{8}$ plane 
Table 3. Torsional angle in R-ionyl derivatives.

\begin{tabular}{|c|c|c|c|}
\hline R group & $\begin{array}{c}\text { Isomer } \\
\beta \text {-ionyl } \\
\text { derivatives }\end{array}$ & $\begin{array}{l}\text { Temperature } \\
\left({ }^{\circ} \mathrm{C}\right)\end{array}$ & $\begin{array}{l}\text { (Torsional } \\
\text { angle) }\end{array}$ \\
\hline $\mathrm{CN}(5)$ & $\begin{array}{l}\text { trans } \\
\text { cis }\end{array}$ & $\begin{array}{r}29 \\
-24 \\
29 \\
-40\end{array}$ & $\begin{array}{l}26 \cdot 34 \\
26 \cdot 34 \\
32-41 \\
30-39\end{array}$ \\
\hline $\mathrm{COOH}(\underline{3})$ & $\begin{array}{l}\text { trans } \\
\text { cis }\end{array}$ & $\begin{array}{l}29 \\
29\end{array}$ & $\begin{array}{l}26-34 \\
36-49\end{array}$ \\
\hline $\mathrm{COOCH}$ & $\begin{array}{l}\text { trans } \\
\text { cis }\end{array}$ & $\begin{array}{l}29 \\
29\end{array}$ & $\begin{array}{l}28-36 \\
33-45\end{array}$ \\
\hline $\mathrm{CH}_{2} \mathrm{OCCH}_{2}$ & $\begin{array}{l}\text { trans' } \\
\text { cis }\end{array}$ & $\begin{array}{l}29 \\
29\end{array}$ & $\begin{array}{l}28-36 \\
37-50\end{array}$ \\
\hline $\mathrm{CH}_{3} \mathrm{CHOH}(2)$ & $\begin{array}{l}\text { trans } \\
\text { cis }\end{array}$ & $\begin{array}{r}29 \\
29 \\
-\quad 7\end{array}$ & $\begin{array}{l}26-34 \\
33-43 \\
32-42\end{array}$ \\
\hline $\begin{array}{c}\left(\mathrm{CH}_{3}\right)_{2}-\mathrm{C}-\mathrm{OH} \\
(6)\end{array}$ & $\begin{array}{l}\text { trans } \\
\text { cis }\end{array}$ & $\begin{array}{r}27 \\
40 \\
-40\end{array}$ & $\begin{array}{l}28-36 \\
40-53 \\
37-51\end{array}$ \\
\hline
\end{tabular}

respectively. These coupling constant results clearly demonstrate that the ring is twisted out of plane in bath cis and trans isomers, although specific value for the angle must be regarded as approximate. The angles measured is an average over the torsional ascillations. The torsional angle for trans $\beta$-ionyl derivatives is independent of the substituents whereas for cis-isomers it seems to depend an them indicating the source of steric strain in 7-cis isomers to be the interaction of $\mathrm{CH}_{3}-18$ or $\mathrm{CH}_{3}-16,17$ with substituents on $\mathrm{C}-8\left(\mathrm{CH}_{3}\right.$ group in the case of retinal).

\subsection{DNMR study}

The abave results clearly demonstrate that cis- $\beta$ ionyl derivatives and in turn 7-cis isomers of retinyl derivatives and carotenoids prefer the twisted ring chain conformation. The large steric hindrance in these molecules gives rise to a large barrier for the conformational equilibrium involving rotation around 6-7 single bond. DNMR spectroscopy has been extensively used in the study of fast exchange rate processes in cyclic as well as acyclic molecules (Binsch 1968). The applicability of the above technique to our system is readily realised, considering the magnetic non-equivalence of gem-dimethyl group $\left(\mathrm{CH}_{\mathrm{s}}-16,17\right)$ in the frazen conformation compared to the equivalence under fast rotation around 6-7 bond, 


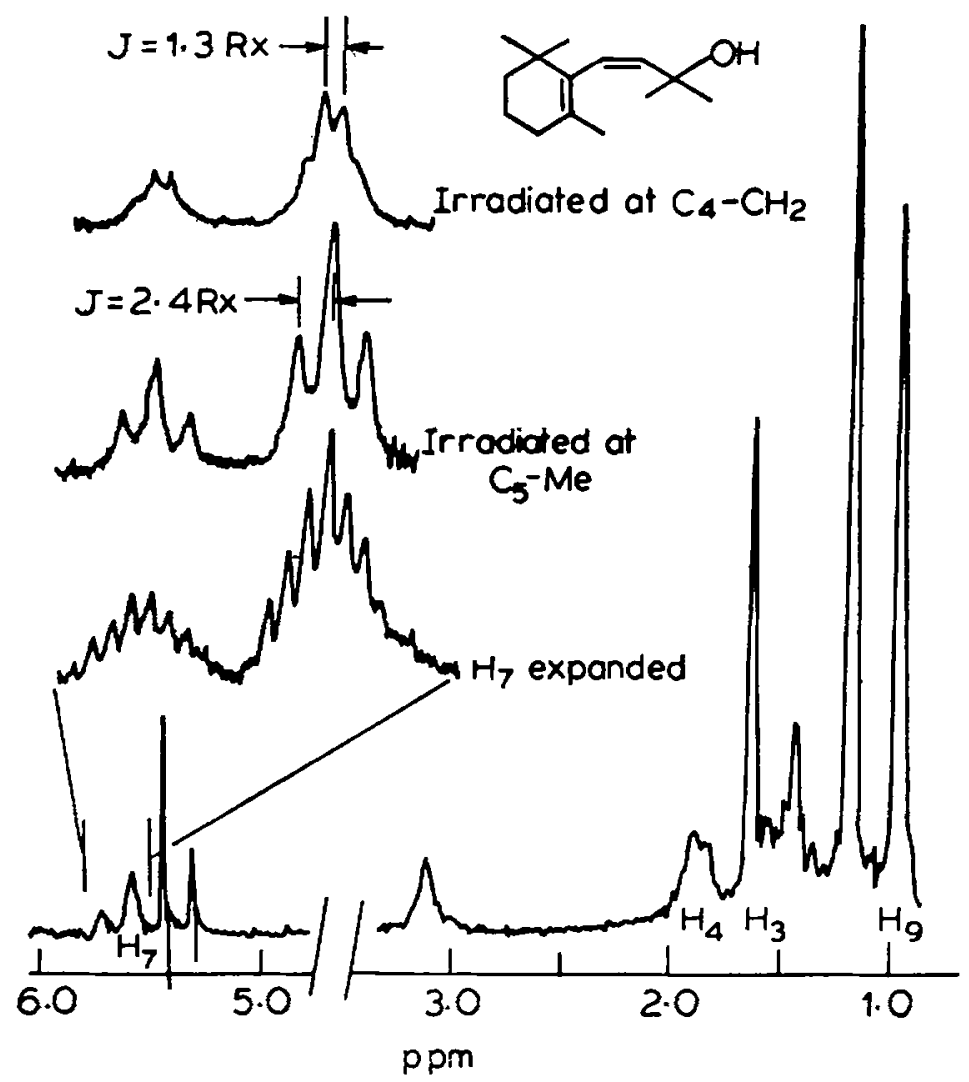

Figure 1. NMR spectrum of cis 6 .

The geminal methyl groups $\left(\mathrm{CH}_{3}-16,17\right)$ which appear as sharp singlet in pmr spectra at ambient temperature for 4 and $6\left[\mathrm{R}=\mathrm{CH}_{3} \mathrm{CHOH}\right.$ and $\left.\left(\mathrm{CH}_{3}\right)_{2} \mathrm{C}-\mathrm{OH}\right]$ turns into a doublet at low temperatures. Similarly $\mathrm{C}_{13}$ resonance of geminal methyl carbons of $\underline{4}$ and $\underline{6}$ show magnetic non-equivalence due to restricted rotation at low and room temperatures respectively by appearing as two singlets. The pmr spectra of these compounds $(2, \underline{3}, \underline{4}$ and $\underline{6}$ ) were recorded at various temperatures and the $\triangle G^{+}$, the activation free energy for interconversion or exchange between the two structurally equivalent rotational isomers was calculated from their rate at the coalescence temperature (Ramamurthy et al 1972). The results are shown in table 4. The coalescence temperature as well as $\Delta G^{+}$of these compounds seems to indicate the presence of large steric hindrance that is dependent on the size of the substituents at C-8.

The two ratamers of the two structurally equivalent ratational isomers of $\underline{6}$ must be enantiomers due to the production of molecular asymmetry. Based on the energy barrier calculated above, we did nat expect this to be resolvable. Instead the presence of two enantiomers were shown by using an optically active shift reagent. The pmr spectra of $\mathbf{6}$ in the presence of fluoroshift and Eu-optishift reagents were recorded at $20^{\circ} \mathrm{C}$ (Whitesides and Lewis 1970; Goering et al 1971). The spectra show the expected downfield shift of signals in both cases (figures 2 and 3). In the former, geminal methyl signals $\left(\mathrm{CH}_{3}-16,17\right)$ and the signals due 
Table 4. Rotational barrier in cis- $\beta$-ionyl derivatives.

\begin{tabular}{|c|c|c|c|c|}
\hline $\mathbf{R}$ & Solvent & $\begin{array}{l}\text { Coalescence } \\
\text { temperature }\end{array}$ & $v_{\mathrm{Hz}}-v_{A}$ & $\begin{array}{c}\Delta G \\
\text { k. cal/mole }\end{array}$ \\
\hline $\mathrm{CH}_{2} \mathrm{OH}$ & $\begin{array}{l}\text { Carbon disulphide } \\
\text { Vinyl chloride }\end{array}$ & $\begin{array}{l}-60 \mathrm{C} \\
-62\end{array}$ & $\begin{array}{l}4 \cdot 0 \\
\ldots\end{array}$ & $\begin{array}{c}11 \cdot 2 \\
\ldots\end{array}$ \\
\hline $\mathrm{CH}_{3} \mathrm{CHOH}$ & $\begin{array}{l}\text { Chloroform } \\
\text { Carbon disulphide }\end{array}$ & $\begin{array}{l}-32 \\
-35\end{array}$ & $\begin{array}{l}. . \\
. .\end{array}$ & $\ddot{. .}$ \\
\hline$\left(\mathrm{CH}_{3}\right)_{8} \mathrm{C}-\mathrm{OH}$ & $\begin{array}{l}\text { Chloroform } \\
\text { Freon-12 } \\
\text { Vinyl chloride }\end{array}$ & $\begin{array}{l}20 \\
20 \\
22\end{array}$ & $\begin{array}{l}2 \cdot 8 \\
\because \\
\cdots\end{array}$ & $\begin{array}{c}15 \cdot 7 \\
. . \\
.\end{array}$ \\
\hline $\mathrm{COOH}$ & Carbon disulphide & -50 & 15.6 & $11 \cdot 0$ \\
\hline
\end{tabular}
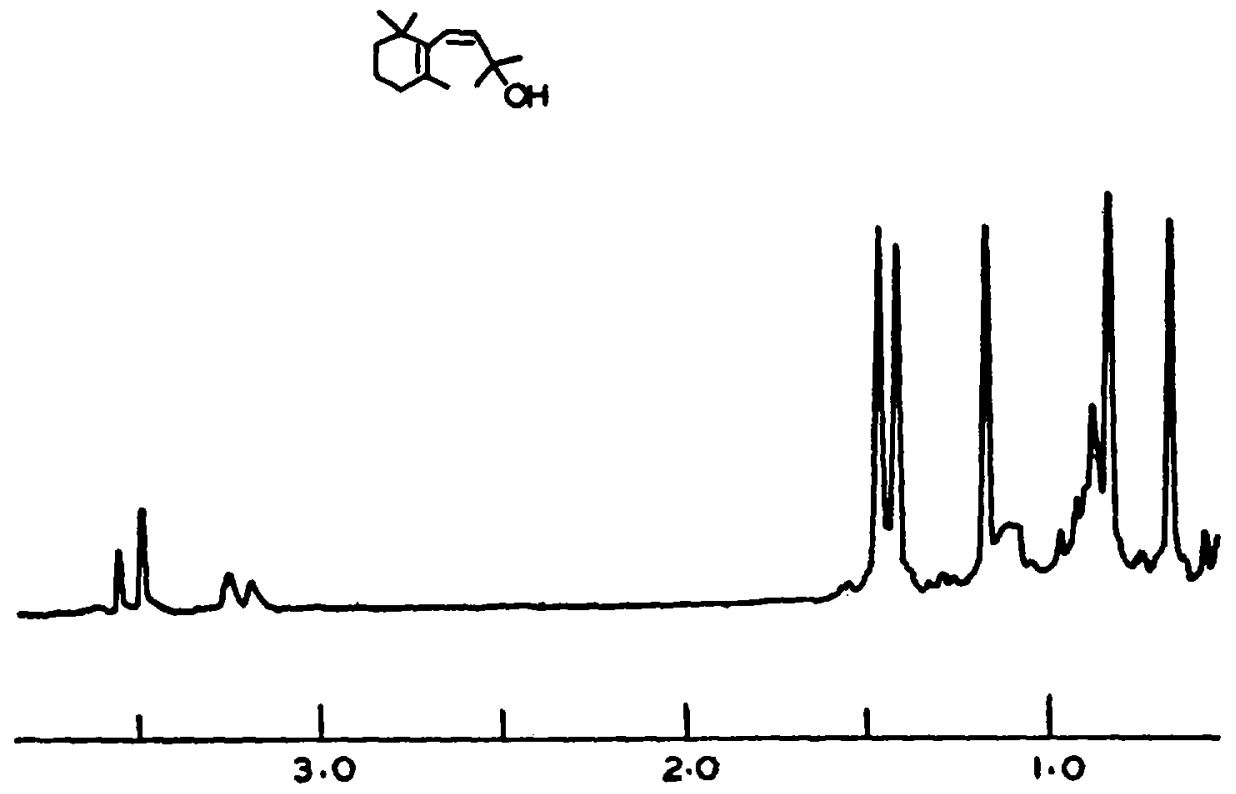

Figure 2. NMR spectrum of cis 6 in the presence of fluoroshift reagent.

to $\mathrm{CH}_{3}-19,19^{1}$ appear as twa doublets due to the frozen out conformation. On the other hand in the presence of Eu-aptishift reagent, signals due to two enantiomers of 6 are clearly visible $\left(\mathrm{H}_{8}\right.$, two doublets; $\mathrm{CH}_{3}-18$, two singlets; $\mathrm{CH}_{3}-19,1^{\circ}$ two doublets) as shown in figure 3. Thus, the above DNMR and nmr results in the presence of shift reagents clearly demonstrate that 7-cis isomers of $\beta$-ionyl derivatives exist in non-planar forms with a twist around 6-7 single bond. This skewed geometry is expected to disfavour conjugation of the ring double bond with the rest of the chain. In confirmation of the above results we found that 7 -cis $\beta$-ionol has a higher singlet excited state energy than 7-trans isomer (7-cis, $210 \mathrm{~nm}$; 7-trans, $235 \mathrm{~nm}$ ). 


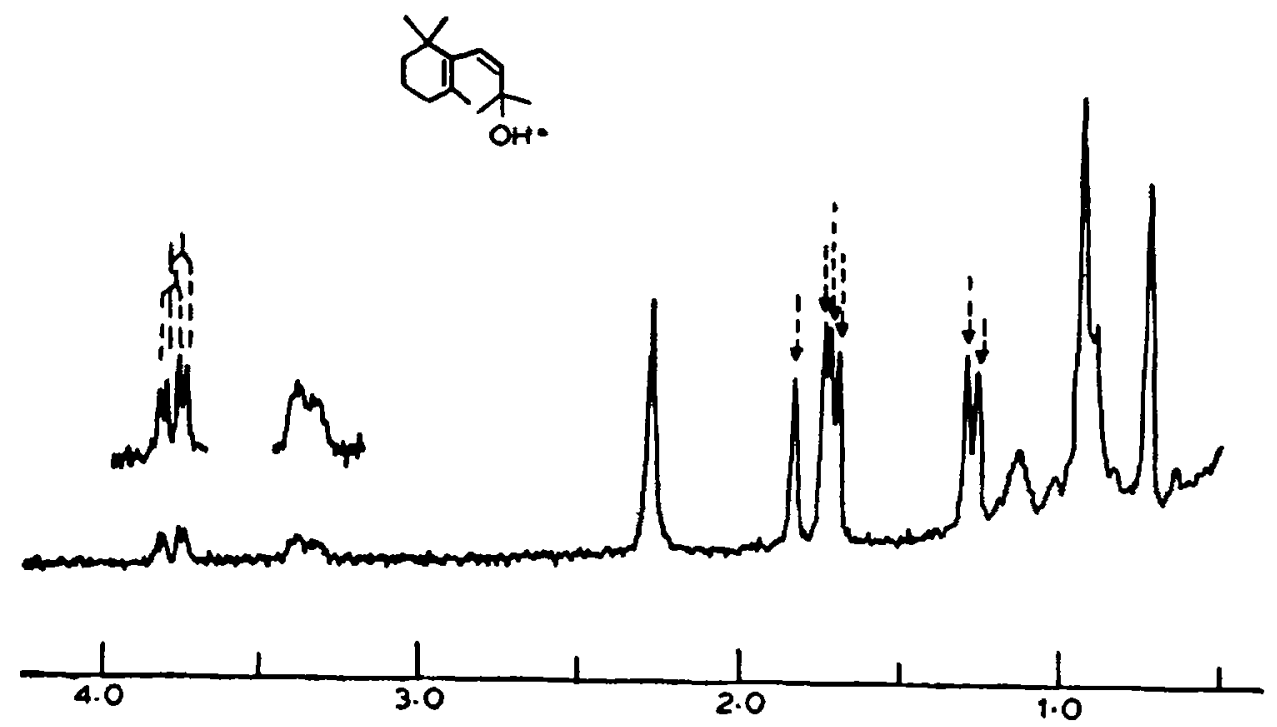

Figre 3. NMR spectrum of cis 6 in the presence of Euro optishift reagent.

In conclusion we have clearly established that 7-cis isomers of $\beta$-ionyl derivatives and in turn 7-cis isomers of retinyl derivatives prefer a non-planar arrangement and this non-planarity brings about resonance destabilisation as was originally predicted.

\section{Acknowledgements}

RSHL thanks United States Public Health Service and the National Science Foundation for financial support and VR expresses appreciation for the untiring encouragement of Profs C N R Rao and M V George. VR acknowledges financial support from the Department of Science and Technology, Government of India.

\section{References}

Binsch Q 1968 Top. Stereochem. 397

Favle $\mathrm{H}$ and Karrer P 1961 Helv. Chim. Acta 441261

Goering H L, Bikenberry J N and Commer G S 1971 J. Am. Chem. Soc. 935913

Jantelat M, Grutzoner J B and Roberts I D 1970 Proc. Natl. Acad. Sci. 65288

Onhaik W $1956 \mathrm{~J}$. Am. Chem. Soc. 782651

Patel D J 1969 Nature 221825

Pauling I 1939 Fortsch. Chem. Org. Narurst. 3203

Pauliog L 1949 Helv. Chim. Acta 322241

Ramamurthy V, Bopp T T and Liu R S H 1972 Tetrahedron Lett. 3915

Ramamurthy V and Liu R S H $1976 \mathrm{~J}$. Am. Chem. Soc. 982935

Ramamurthy V, Tustin G, Yau C C and Liu R S H 1975 Tetrahedron 31193

Russel S W and Weodon B C L 1969 Chem. Commun. 85

Stothers J B 1972 Carbon-13 NMR Spectroscopy (New York : Academic Press)

Wald O, Brown P K, Hubbard R and Orshnik W 1955 Proc. Natl. Acad. Sci. 41438

Wald G, Brown P K, Hubbard R and Orshnik W 1956 Proc. Natl. Acad. Sci. 42578

Whitesides O M and Lewis D W $1970 \mathrm{~J}$. Am. Chem. Soc. 926976 